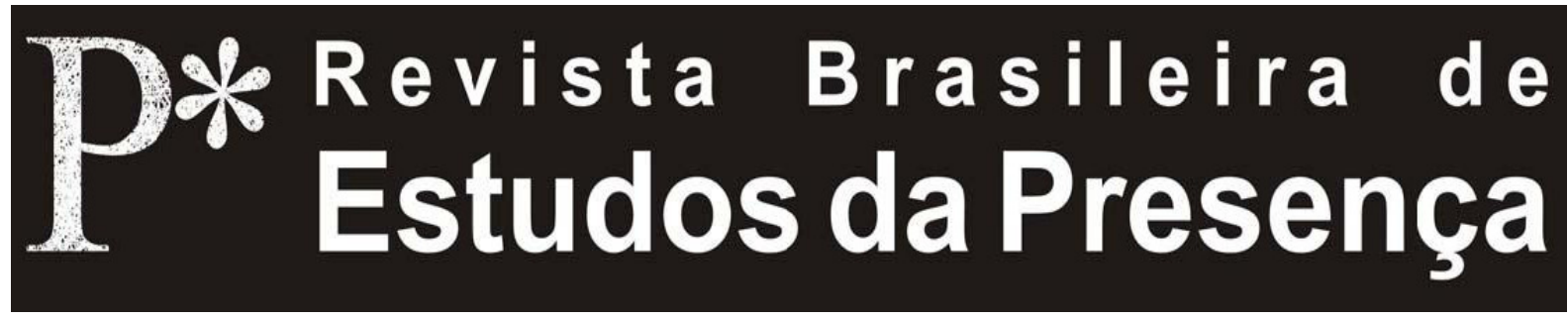

DOI - http://dx.doi.org/10.1590/2237-266036412

ISSN 2237-2660

\title{
Teatro Pobre: meta ou caminho?
}

Resenha sobre a obra

GROTOWSKI, Jerzy. Para um Teatro Pobre. Brasília: Teatro Caleidoscópio \& Ed. Dulcina, 2011.

\section{Lidia Olinto}

Universidade Estadual de Campinas - Unicamp, Campinas, SP, Brasil

RESUMO - Teatro Pobre: meta ou caminho? - Este texto é uma resenha do livro Para um Teatro Pobre, de Jerzy Grotowski, recentemente publicado no Brasil com nova tradução de Ivan Chagas. Primeiramente, apresenta-se um breve histórico desse livro, que é uma das mais importantes obras escritas na área de Artes Cênicas, uma vez que contribuiu expressivamente para estabelecer novos parâmetros para o fazer teatral, nas últimas décadas do século XX. Após esse breve histórico, são sinteticamente descritas as principais ideias e conceitos apresentados ao longo do livro, tais como as noçóes de: 'teatro pobre', 'ator santo' e 'via negativa'. Por último, a nova tradução é criticamente comentada, dando destaque à mudança do título feita por Ivan Chagas, antes traduzido como Em Busca de Um Teatro Pobre.

Palavras-chave: Teatro. Ator. Atuaçáo. Grotowski. Teatro Laboratório.

ABSTRACT - Poor Theatre: goal or path? - This article is a critical review of the book Towards a Poor Theatre by Jerzy Grotowski, recently published in Brazil with a new Portuguese version by Ivan Chagas. This book is considered one of the most important works ever written in the field of the Performing Arts, having contributed to setting new standards for theatre as a practice in the late twentieth century. In this review a brief background of the book is presented and its main ideas are briefly described, such as the notions of: 'poor theater', 'holy actor' and 'via negativa'. Ivan Chagas's translation is critically discussed, especially his change of title.

Keywords: Theater. Actor. Acting. Grotowski. Laboratory Theater.

RÉSUMÉ - Théâtre Pauvre: objectif ou chemin? - Cet article est un résumé critique du livre Vers un Théatre Pauvre de Jerzy Grotowski, récemment publié au Brésil avec une nouvelle traduction d'Ivan Chagas. Ce livre est considéré comme l'un des ouvrages les plus importants dans le domaine des arts du spectacle, ayant contribué à établir de nouveaux paramètres pour la pratique théâtrale, aux dernières décennies du XX ${ }^{\text {ème }}$ siècle. Après une brève présentation de l'histoire de ce livre, les principaux concepts introduits par l'auteur sont ici soulignés, tel que les notions de 'théâtre pauvre', d'acteur saint' et de 'voie négative'. La traduction est aussi commentée, notamment le changement du titre dans cette nouvelle édition.

Mots-clés: Théâtre. Acteur. Performance. Grotowski. Théâtre Laboratoire. 
Para um Teatro Pobre é a reedição, com tradução de Ivan Chagas, do renomado livro de Jerzy Grotowski, Towards a Poor Theatre, publicado em 1968 pelo Odin Teatret e, no Brasil, em 1971, sob o título de Em Busca de Um Teatro Pobre e com tradução de Aldomar Conrado. Trata-se de uma publicação relevante para o campo teatral, pois, a despeito da grande importância histórica desta obra, sua última edição encontrava-se esgotada há muitos anos. Embora tenha a assinatura de Grotowski como autor, o livro reúne textos produzidos por diferentes autores, em momentos distintos, com formato e função que igualmente se distinguem, mesmo quando a autoria é de Grotowski. São artigos publicados em jornais e revistas, transcriçôes de entrevistas concedidas por Grotowski na década de sessenta e textos que descrevem e analisam os espetáculos ou os treinamentos desenvolvidos pelo Teatro Laboratório, grupo polonês dirigido por Grotowski e por Ludwik Flaszen, autor de alguns dos textos do livro.

No prefácio, Peter Brook afirma que, no que se refere à investigação dos processos psicofísicos do ator, a contribuição metodológica de Grotowski é impar, e, talvez, só possa ser comparada à de Stanislavski. Dentro dessa perspectiva, a edição de Towards a Poor Theatre teve historicamente um papel crucial na medida em que se tornou, nas décadas de setenta e oitenta, o principal veículo de divulgação internacional das ideias inovadoras de Grotowski (Barba, 2006). Tendo sido traduzido para diversas línguas, esse livro influenciou muitos artistas e companhias de diversos países, principalmente na Europa e nas Américas, transformando-se em uma espécie de "bíblia do teatro moderno", na expressão usada por Osinski (1979, p. 87). No Brasil, por exemplo, as ideias grotowskianas vêm, desde os anos setenta até hoje, diretamente ou indiretamente influenciando grupos teatrais importantes, tais como: Asdrubal Trouxe o Trombone, Teatro Oficina, Teatro da Vertigem e outros, como observaram Mencarelli (2004), Garcia (2005) e Carreira (2005).

No entanto, ao perceber que Towards a Poor Theatre estava se transformando em uma espécie de 'novo modelo' de teatro, Grotowski inúmeras vezes criticou esse processo de canonização, através do qual suas ideias e exercícios convertiam-se em um tipo de 'receita' para outros grupos. Nas suas palavras: "[...] por toda a parte há sempre essa necessidade e essa falsa esperança em receitas que possam resolver todos os nossos problemas criativos. Essas receitas 
não existem" (Grotowski, 2007, p. 168). Por isso, no início dos anos setenta, Grotowski fazia questáo de referir-se ao seu livro como um 'diário de bordo' das montagens precedentes do Teatro Laboratório, afirmando, inclusive, que muitos dos pressupostos teóricos e procedimentos metodológicos ali descritos não correspondiam àqueles que estavam, naquele momento, guiando as investigaçóes do grupo (Grotowski, 1972). Nesse sentido, essa é uma obra que não deve ser encarada como um conjunto coeso e homogêneo de propostas para a arte teatral - como muitas vezes foi lida -, mas sim como uma compilação de textos que permite ao leitor perceber tanto continuidades como mudanças significativas na trajetória de pesquisa de Grotowski e seus companheiros.

A iniciativa de retraduzir esse livro pode ser relacionada a um interesse maior observável nos últimos anos pelo legado grotowskiano. Uma série de iniciativas por parte da editoração brasileira ${ }^{1}$ vem ampliando consideravelmente o acesso do público a textos até então inéditos. Também nos últimos anos, pesquisas e eventos acadêmicos relevantes no cenário nacional ${ }^{2}$ estão, não só renovando a reflexão sobre a obra de Grotowski, como possibilitando que se repense certas leituras canônicas de sua teoria e práxis cênica.

A seguir, serão sinteticamente apresentadas algumas ideias que fizeram da publicação de Para um Teatro Pobre uma referência teórica decisiva na constituição de novos parâmetros para o fazer teatral do século XX. Note-se que os textos náo são todos do mesmo ano e que as ideias neles contidas náo estão presentes em toda a obra de maneira unívoca.

No primeiro capítulo, homônimo ao livro, Para um teatro pobre, e no segundo, $O$ novo testamento de teatro, Grotowski expóe sua acepçáo de um teatro ascético (teatro pobre) que investiria propositalmente "[...] naquilo que acontece entre o espectador e o ator" (p. 25). Assim, através do conceito de 'teatro pobre', Grotowski defende que a especificidade do Teatro está na relação ator-público, pois seria ela que distinguiria em essência a Arte Teatral do Cinema e da Televisão. Por essa razão, a criação cênica deveria, na visão do diretor polonês, voltar-se para a exploração da psicofisiologia do ator, e não para os efeitos visuais e sonoros produzidos pelos recursos materiais da encenação, ou seja, pela iluminação, cenário, trilha sonora, figurino e etc. Entretanto, náo se trata exatamente de eliminar da cena 
os elementos 'externos' ao ator, como o cenário ou o figurino, mas sim de encarar a atuação como o principal pilar da criação teatral.

Nesses mesmos textos, o diretor também apresenta e discute a diferença entre as noções de 'ator cortesão' e de 'ator santo', sendo o primeiro aquele que teria como foco agradar ou impressionar o público, utilizando-se, para isso, de truques e artifícios técnicos. Já o 'ator santo' seria aquele que, através de uma técnica indutiva, "[...] se sacrifica e revela seus aspectos mais íntimos e mais dolorosos" (p. 27) diante do espectador. Dentro do prisma da 'santidade', o diretor fala da atuaçáo como um "estado de transe" (p. 29), ou seja, um ato de autodoação que requer uma mobilização integral das forças físicas e psíquicas do ator. Dessa maneira, Grotowski defende que o ator não deve atuar para o espectador, nem para si mesmo, mas sim para algo que surge de dentro e se direciona para fora.

Já a expressão 'via negativa' sintetiza uma concepção de treinamento e técnica do ator como "uma técnica negativa e náo positiva" (p. 164), cujo objetivo principal não seria acumular habilidades físicas e vocais, mas sim eliminar resistências e bloqueios psicofísicos pessoais para a realização 'plena' do ato criativo, "[...] acabando, assim, com o lapso de tempo entre impulso interior e reação exterior" (p. 13). A arte teatral também é apontada como um espaço de provocação, de confronto e não de identificação com valores morais e mitos sociais. Além disso, Grotowski discorre sobre a relação ator-diretor como podendo ser, em sua visão, um "nascimento duplo compartilhado" (p. 20), ou seja, um processo no qual há idealmente um enriquecimento pessoal mútuo.

Em Teatro é encontro, Grotowski enfatiza o teatro não como a ilustração de um texto dramático, mas sim um lugar onde há um encontro: o encontro do ator como ele mesmo, do diretor com o ator, e de ambos com o texto dramático. Nesse prisma, a funçáo do texto seria a de "uma espécie de bisturi" (p. 45) que permitiria uma abertura do ator (e do diretor também) àquilo que está oculto dentro dele mesmo, ou, em outras palavras, o texto serviria como "[...] um instrumento para fazer um corte transversal em si mesmo" (p. 166).

Em $A$ técnica do ator, o diretor aborda a noção de partitura, apresentando-a como um conjunto de "[...] elementos de contato humano: dar e receber" (p. 167) que, desse modo, não permitiria a mecanização da atuação. E, no capítulo $O$ discurso de Skara, Grotow- 
ski apresenta certos princípios pragmáticos para o trabalho do ator, especificamente as noçôes de: 'reação', 'impulso', 'contato', 'associação pessoal' e 'corpo-memória' (ou 'corpo-vida'). Essas noçóes, cujas definiçôes teóricas e aplicaçôes na prática cênica estão intimamente imbricadas, passam, após 1965, a ocupar um papel importante nas pesquisas do Teatro Laboratório em torno da organicidade do ator. Nesse mesmo texto, que é a transcrição de uma palestra, Grotowski enfatiza como elementos igualmente fundamentais do trabalho do ator as noçóes de partitura e espontaneidade, presentes de modo articulado e complementar, tanto no treinamento como na criaçáo de uma cena. A atuação também passa a ser vislumbrada e almejada como um "ato total" (p. 94), quer dizer, uma ação que idealmente envolveria todas as camadas psicofísicas do ser e que, consequentemente, levaria o ator a transcender a superficialidade e os dualismos da vida cotidiana.

Em Um encontro americano, Grotowski faz uma reflexão sobre a ética artística. Segundo sua concepção, seria fundamental para o ator 'correr riscos', ou seja, penetrar em um processo de autoconhecimento e negar a repetiçáo de caminhos já trilhados, o que o levaria inevitavelmente a truques e estereótipos. Nesse sentido, ele aponta o paradoxo de que, para se ter um resultado, é preciso náo procurar por ele, uma vez que enfocá-lo bloquearia o processo criativo.

No último texto do livro, Declaração de princípios, Grotowski destaca a importância ética do silêncio, da discrição, da autodisciplina, da pontualidade, do respeito mútuo e da inteireza no cumprimento dos mínimos detalhes do processo criativo para proteger a criação individual e garantir a penetração concreta do ator em um processo de autoconhecimento e transformaçáo existencial.

Há também no livro textos que analisam alguns dos espetáculos produzidos pelo Teatro Laboratório na década de sessenta-Akropolis, Dr.Faustus e O Principe Constante - e dois capítulos que descrevem o treinamento executado pelos atores do grupo polonês em períodos distintos: 1959-1962 e 1966. Essas duas descriçóes permitem ao leitor perceber mudanças concretas no treinamento do grupo que, após 1965, passa a ter um "método de controle mais orgânico" (Grotowski, 2007, p. 138), quer dizer, uma nova abordagem na qual há uma maior fluidez entre os aspectos corporais, vocais e psíquicoimagéticos dos exercícios. 
Antes de concluir, cabe ainda comentar brevemente a tradução de Ivan Chagas. Evidentemente que a intenção de uma nova tradução é, em certa medida, reavaliar termos e expressóes utilizados anteriormente. Nesse sentido, é pressuposto encontrar uma série de pequenas ou grandes modificaçôes em relação à primeira tradução. Entretanto, a modificação do título de um livro já renomado só se justificaria se, nessa mudança, algum aspecto relevante da obra fosse apresentado, ou se a primeira traduçáo merecesse ser alterada por algum motivo concreto como foi, por exemplo, o caso do livro The Empty Space de Peter Brook (1968), antes traduzido como O Teatro e Seu Espaço (1970) e depois merecidamente retraduzido como $O$ Espaço Vazio (2008). Náo creio ser este o caso da mudança de: Em Busca de um Teatro Pobre por Para um Teatro Pobre, como tradução para título original do livro, Towards a Poor Theatre.

O termo 'towards' é um daqueles termos múltiplos da língua inglesa que, tendo diversos usos e significados, pode ser traduzido para o português por diferentes expressóes ou vocábulos. Dentre as traduções plausíveis para 'towards' está de fato a preposição 'para', mais comumente utilizada que a expressão escolhida por Aldomar Corando, 'em busca de'. Porém, a expressão 'em busca de', além de ser igualmente uma das traduçóes possíveis para 'towards', remete às ideias de caminho e de processo, sendo, portanto, bem mais condizente com o espírito de pesquisador de Grotowski do que a palavra 'para', que conota utilidade e finalidade. Como enfatizaram Osinski (1979), Motta-Lima (2012) e outros teóricos, Grotowski como artistapesquisador esteve até o final de sua vida em contínuo processo de investigação e "inovação terminológica" (Flaszen, 2007, p. 20), ou, como costumeiramente se referia ao seu trabalho de pesquisa, "in statu nascendi" (cf. Osinski, 1979, p. 10). Por isso, frequentemente se autocriticava e advertia seus ouvintes/leitores sobre o perigo existente no estabelecimento de regras e modelos rígidos para o processo artístico. Nesse sentido, a opção pela palavra 'para' parece equivocadamente indicar que o livro é uma espécie de receituário de como fazer para alcançar um teatro pobre, e náo o relato de um caminho 'em busca de' algo. 


\section{Notas}

${ }^{1}$ Refiro-me aqui às publicações de: Trabalhar com Grotowski sobre as ações-físicas (Richards, 2012), Palavras Praticadas: o percurso artístico de Jerzy Grotowski, 1959 -1974 (Motta-Lima, 2012), Avec Grotowski (Brook, 2011), Trabalho de Voz e Corpo de Zygmunt Molik: o legado de Jerzy Grotowski (Campo, 2012), O Teatro Laboratório de Jerzy Grotowski 1959-1969 (Grotowski, 2007 e 2010), A Terra de Cinzas e Diamantes (Barba, 2006).

${ }^{2}$ Refiro-me à realização do Seminário Internacional Jerzy Grotowski: uma vida maior do que o mito (Universidade Federal do Estado do Rio de Janeiro, 2009), às pesquisas de Motta-Lima, Mencarelli e outros pesquisadores brasileiros.

\section{Referências}

BANU, Georges (Org.). Ryszard Cieslak: acteur emblème dês années soixante. Paris: Actes Sud, 1992.

BARBA, Eugenio. A Terra de Cinzas e Diamantes. São Paulo: Perspectiva, 2006.

BROOK, Peter. Avec Grotowski. Rio de Janeiro: Editora Dulcina, 2011.

BROOK, Peter. O Espaço Vazio. Lisboa: Orfeu Negro, 2008.

BROOK, Peter. O Teatro e seu Espaço. Petrópolis: Ed. Vozes Limitada, 1970.

BROOK, Peter. The Empty Space. Nova York: Atheneum, 1968.

CAMPO, Giuliano. Trabalho de Voz e Corpo de Zygmunt Molik: o legado de Jerzy Grotowski. São Paulo: Realizações Ed, 2012.

CARREIRA, André. Grotowski y el Teatro de Grupo em el Brasil. Cuadernos de Picadero, Buenos Aires, Instituto Nacional Del Teatro, n. 5, p. 29-33, mar. 2005.

GARCIA, Silvana. Apocalypsis cum Brasilia Figura: traços da presença de Grotowski no Brasil. Cuadernos de Picadero, Buenos Aires, Instituto Nacional del Teatro, n. 5, p. 3338, mar. 2005.

GROTOWSKI, Jerzy. Para um Teatro Pobre. Brasília: Teatro Caleidoscópio \& Ed. Dulcina, 2011.

GROTOWSKI, Jerzy. Em Busca de um Teatro Pobre. Rio de Janeiro: Civilização Brasileira, 1987.

GROTOWSKI, Jerzy. Meeting with Grotowski. In: The Theatre in Poland, n. 7. Varsóvia: Varsovie Author Agency, 1972. P. 8-10.

GROTOWSKI, Jerzy; FLASZEN, Ludwik; POLLASTRELLI, Carla. O Teatro Laboratório de Jerzy Grotowski (1959-1969). São Paulo: Fondazione Pontedera Teatro/ Perspectiva/SESC-SP, 2007.

KUMIEGA, Jennifer. The Theater of Jerzy Grotowski. London and New York: Methuen, 1985. 
MENCARELLI, Fernando. Grotowski e a Criação Teatral Contemporânea no Brasil. Meditaçóes performáticas latino-americanas II, Belo Horizonte, FALE/UFMG, n. 2, p. 29-37, 2004.

MOTTA-LIMA, Tatiana. Conter o Incontível: apontamentos sobre os conceitos de 'estrutura' e 'espontaneidade' em Grotowski. Sala Preta, São Paulo, USP, n. 5, p. 47-67, 2005.

MOTTA-LIMA, Tatiana. Palavras Praticadas: o percurso artístico de Jerzy Grotowski, 1959-1974. São Paulo: Perspectiva, 2012.

OSINSKI, Zbigniew. Grotowski's Laboratory. Warsaw: Interpress Publishers, 1979.

RICHARDS, Thomas. Trabalhar com Grotowski sobre as Açóes Físicas. São Paulo: Perspectiva, 2012.

Lidia Olinto possui graduação em Artes Cênicas pela Universidade Federal do Estado do Rio de Janeiro. Fez mestrado em Artes da Cena na Universidade Estadual de Campinas com bolsa concedida pela CAPES, sob orientação do Prof. dr. Matteo Bonfitto e co-orientação da Prof. dra. Tatiana Motta Lima (UNIRIO). Atualmente está no doutorado no mesmo programa e sob orientaçáo dos mesmos professores e também com bolsa da CAPES.

E-mail: lidiaolinto@gmail.com

Recebido em 17 de novembro de 2012

Aprovado em 18 de dezembro de 2012 